\title{
Effect of Digital Technologies on the Energy Sector. International Experience. Russian Opportunity
}

\author{
Elena Balashova \\ Higher school of management and \\ business \\ Peter the Great St. Petersburg \\ Polytechnic University \\ St. Petersburg, Russia \\ elenabalashova@mail.ru \\ Sergei Schislyaev \\ Saint-Petersburg scientific center RAS \\ St. Petersburg, Russia \\ igms@smtru.ru
}

\author{
Ksenia Maiorova \\ Department of International Economic \\ relations \\ State Marine Technical University \\ St. Petersburg, Russia \\ xs-ksu123@mail.ru
}

\author{
Elena Schislyaeva \\ Department of International \\ Economic relations \\ State Marine Technical University \\ St. Petersburg, Russia \\ schislyaeva@smtu.ru
}

\begin{abstract}
The existing technological structure of the electric power industry has reached the limit of its efficiency and in the future will lose its high competitiveness compared to the digital energy solutions. One of the key global trends in the development of the fuel and energy complex in current-day realities is the modification of digital and intelligent process solutions in the management of production capacities of the energy industry.
\end{abstract}

Energy digitalization in the domestic market as a process has been launched relatively recently, but already now this phenomenon is a positive impact to the development of the fuel and energy complex of our country. Active implementation of digital technologies in the internal and external business processes of enterprises results in innovative business models that ensure the future competitiveness of the industry.

The current-day realities impose their strict requirements for the domestic energy market, and to take the leading positions, the fuel and energy complex of Russia has to create a fundamentally new and powerful platform, which will be based on a set of measures in key trends mentioned in the Ministry of Energy project "Digital Energy".

This study asses the current stage of "digital" energy development in the Russian market. The specifics of "digital" technologies related to the energy industry are evaluated. The main point and features of the implementation of "digital" technologies in the industry of the fuel and energy complex are realized. The business processes of the industrial enterprise EDF are analyzed using the digital technologies. The main trends for development of "digital" energy in the Russian Federation are identified.

The digital technologies propose creation and implementation of new methods for communication with consumers. The digital technologies affect all critical elements of the organization as such the possibility of integrated survey concerning the readiness for these transformations. For effective development in conditions of digital transformation in the energy sector, the enterprises need to have a suitable management strategy and a number of competencies. There is active work going on implementation of innovative solutions relating to production at enterprises, creation of new specific, unique oversight functions at the state level, transformation of professional education to train future specialists in the field of digital energy.

The key results of implementation of these measures shall be upgrading the efficiency of enterprises activity in the fuel and energy sector of the Russian economy, optimization of the business processes of "smart" gas distribution networks and electric "smart" networks, enhancement of the level of technical condition of production assets of the electric power industry and reliability growth of power supply to consumers.

Keywords - digitalization, energy, industrial economics, digital economics, distribution networks, "smart” technologies.

\section{INTRODUCTION}

2017 was a significant year for development of the fuel and energy complex of the Russian Federation through the active formation and implementation of a new policy orientation, namely the transition to a digital economy. With a view modification of the main production capacities of the energy sector of the Russian Federation and creation of the conditions for introduction of innovative technologies in the digital platform solutions of the national fuel and energy complex, the Ministry of Energy of the Russian Federation formed the industry project "Digital Energy". Taking into account the priorities setting out by the President of the Russian Federation, which were approved in the national program "Digital Economy of the Russian Federation" in 2017, the project "Digital Energy" is going to create a new purposive approach to the vision of the conceptual system "energy digitalization" and its active implementation in electric power production to create a new national technological base for its further development and generation of proposals to improve the competitiveness of the energy industry [1].

The existing technological structure of the electric power industry has reached the limit of its efficiency and in the future will lose its high competitiveness compared to the digital energy solutions. The conceptual system of "digital" energy is multifaceted and diversified that is a problem, on the one hand, 
due to the variety of opinions. However, on the other hand, this category may be the only solution to a fundamental change in the internal architecture and management of the fuel and energy complex.

Based on the above, the aim of the study is to determine the features and main aspects of digital technologies effect on the electrical power industry in the context of global digitalization. In connection with the established goal, it is necessary to solve the following issues:

- To characterize the current stage of "digital" energy development;

- To consider the "digital" technology specifics in the energy sector;

- To realize the main point and features of the implementation of "digital" technologies in the industry of the fuel and energy complex;

- To analyze the business processes of the industrial enterprise EDF using the digital technologies;

- To identify the main trends for development of "digital" energy in the Russian Federation [2].

\section{MATERIALS AND METHODS}

This study was made based on scientific books on the issues raised, the regulatory framework of the Russian Federation in the field of "digital" energy was analyzed, and the international experience of the power supplier was studied in the "digitalization" conditions.

Based on the analysis of the above sources, the following assumptions were made, namely:

- The "digital" technologies propose creation and implementation of new methods for communication with consumers.

- The "digital" technologies affect critical elements of the organization as such the possibility of integrated survey concerning the readiness for these transformations.

- The enterprises of the fuel and energy complex need to have a suitable management strategy and a number of competencies for effective development in the currentday realities;

- There is an active work going on implementation of "digital" solutions relating to production at enterprises, creation of new specific oversight functions at the state level, transformation of professional education to train future specialists in the field of digital energy, having the unique competence.

\section{RESULTS}

The existing technological structure of the electric power industry has reached the limit of its efficiency and in the future will lose its high competitiveness compared to the digital energy solutions. One of the key global trends in the development of the fuel and energy complex in current-day realities is the modification of digital and intelligent process solutions in the management of production capacities of the energy industry.

Active implementation of digital technologies in the internal and external business processes of enterprises results in innovative business models that ensure the future competitiveness of the industry. The current stage of "digital" energy development in the Russian market was assessed is this study. The specifics of "digital" technologies related to the energy industry are evaluated.

The main point and features of the implementation of "digital" technologies in the industry of the fuel and energy complex are realized. The business processes of the industrial enterprise EDF are analyzed using the digital technologies. The main trends for development of "digital" energy in the Russian Federation are identified.

The national energy market set the priority for the victory in the global technological race and the formulation of a new digitalization benchmark that will ensure combination of the financial and intellectual potentials of our country.

For successful development in conditions of digital transformation, the energy industry enterprises need to have a suitable management strategy and a number of competencies. Thanks to the mentioned components, the organization will be able to more flexibly accept the internal and external changes of its business processes and successfully create innovative business models and products.

Thus, companies in the energy sector will retain their organizational ability regardless of the range activity; they will be able to balance the accumulated and gained experience, creation and modification of new management strategies

Many companies are involved in developing energy of all forms and potentials are embarrassed by the problem of environment and consumers protection, thus, setting themselves the task of "clean" energy production without damage to the consumers' health and the general condition of the ecosystem of our planet. Current digital technologies allow world-class companies to quickly transform their internal business processes, modernize production facilities, and, thus, to get the most effective results from their activities.

The implementation of the latest digital and intelligent technological solutions is one of the key global trends in development of the energy industry at the present stage.

The gradual digitalization of domestic energy was launched as a process only a few years ago, but now, according to the studies made by leading experts in the field of economics, ITtechnologies and the electric power industry, this phenomenon has had an extremely positive impact on the fuel and energy complex development.

Right now, the digitalization subject is central and invariably concerned in almost all discussions regarding the key positions of the energy industry, as well as the main trends for development of this sector of the Russian economy.

However, in addition to up-to-date technologies, it is necessary to change the approach not only to the process vision, but also to the management itself. As Alexey Teksler, the First Deputy Minister of Energy of the Russian 
Federation said in an interview: "The digitalization is not the pro-technology; the digitalization is a change in lifestyle" [3]. Due to active development of the digital technologies, both internal and external business processes of enterprises are changing resulting in the new business models that become a key factor of providing the future competitiveness. In this case, the digitalization being a phenomenon affects not only the optimization of management decisions and enterprises cost reduction, but also acts as a guarantor on the reliability of energy systems, what the state is primarily interested in.

Over the past five years, great changes have occurred in all sectors of the fuel and energy complex due to implementing the unique innovative technologies and developing the advanced digital products. The "smart grids" technologies, virtual prognostics and monitoring of the generating equipment state, as well as dispatching of energy facilities to improve the quality of energy supply are being actively implemented within the energy sector. The "smart grids" technologies to be considered as the basis for electric power industry modernization and improvement have been actively used in the European companies over the past few years [4]. The accumulated experience of strategic developments and managerial concepts in the field of intelligent digital energy in different countries of the world shows that its creation is aimed not only at overcoming certain engineering, economic or managerial tasks, but also at implementing the system process platform that will meet the energy needs of the new digital economy.

The advanced technologies used in networks based on adapting the equipment specifications depending on the modesetting situation, active interaction with generation and consumers allow to create an efficiently functioning system where modern information-diagnostic systems, automation systems for all elements control involved in production processes, transferring, distribution and consumption of electric power. The electric network turns from a passive device for transferring electric power distribution into an active element, the parameters and characteristics of which vary depending on the requirements of real-time operation modes, in which all participants of the electric power market (generation, network, consumers) take an active part in the processes of electric power transferring and distribution.

To implement this new function, the networks shall be equipped with modern high-speed devices of power electronics and electric machine gate systems, systems that provide on-line information on network operation modes and the state of various types of electrical energy storage devices (accumulators), and consumers become active participants in electric power distribution and consumption process [5].

A change of concepts system of the distribution network, development of information and communication technologies, improvement of individual components of energy conversion, advances in the field of devices and systems of protection against failures promoted to the appearance of new technologies that will affect the development of the electric power system. A few specific examples of such technologies are given below:
- Distributed energy that is rapidly developed and equipped with adjusted "plug-and-play" devices automatically connected.

- Intelligent or communication meters. Some countries have started large-scale projects implementation to replace conventional meters in power consumer houses with smart meters, which allow taking the readings remotely and also serve as a portal for other purposes related to the quality of electric power and energy services.

- Actuators integrated into the electric power system. Generally, these devices are based on high-power electronics and are used to more effectively control power flows or other network variables, such as voltage or short-circuit currents. They can also provide capabilities for managing network architectures in emergency situations.

- Quick-acting switching devices and intelligent protection. As a result of the studies, significant advances were made in the field of switching devices that led to cost decreasing and service life increasing. Protection has become more effective and can independently adapt to the environment.

- High-performance and cost-effective sensors associated or not associated with the existing devices: For example, distribution networks are equipped with ineffective measuring instruments providing a problem of monitoring of these networks. The presence of lowcost sensors combined with appropriate communication capabilities provides for the additional prospects for monitoring.

- The advanced EMS (energy management system) and especially DMS (distribution management system): these functions can be located in conventional control centers or can be distributed in distribution networks (a programmed substation or a decentralized data control and acquisition system SCADA) [6]

- Energy storage units. Despite the fact that today the abilities of energy storage on a large scale are extremely scarce and the total cost of this operation is relatively high, significant progress can be expected in the future, especially with regard to the development of intermittent sources of renewable energy.

- Superconducting devices. In particular, they include fault current limiters and superconducting cables in the smart grid at the "damage repair" circuit control level or at the voltage and energy flows control levels.

After several decades of gradual development, energy systems are subject to great changes under influence of such factors as increasing needs for the integration of renewable energy types, equipment obsolescence, insufficient energy efficiency and increasing concern upon the system vulnerability with increasing a number of participants in conditions of energy markets liberalization. The energy systems operation is more and more laborious that finally will require the wide introduction of intelligence in the interests of ensuring safety, economy and efficiency, while creating the prerequisites for the concept of "smart energy systems" [7]. 
Currently, the operation of electric networks is based on four segments due to the structure of the global electric power system [8]:

- The most part of electricity is produced by large power plants located at strategic points of unified energy system;

- The transmission electric network transmits electric power from power plants to energy consumption centers and distribution networks. It is the basis of the entire energy supply system and is equipped with the most advanced equipment. The power grid management is carried out centrally in accordance with the adopted hierarchy;

- Distribution networks take up space between the transmission network and the end user. They are connected to the transmission network through "substations" through transformers. For economic reasons and to simplify operation, distribution networks are mainly used in radial structures. In the absence of significant local energy sources, the distribution networks are featured by unidirectional energy flow (energy always goes in one direction, from the substation to the end user);

- End users, who are mostly passive customers, are characterized by uncontrolled loads and do not participate in the system management.

The first three segments, although they are institutionally separated by clearly defined areas of responsibility, are closely interconnected and subject to the specific physical laws, in particular, production-consumption balance and technical restrictions. In general, this system was developed to produce, transmit and distribute electric energy in accordance with the best standards of quality, safety and economy. This system is considered to be the most complex ever man made, it consists of millions of kilometers of wires and cables, generators, transformers, connection points, etc. It combines several voltage levels, modern protection equipment, checkout facilities and control centers.

The French power system, for example, includes 1300 $000 \mathrm{~km}$ of power lines and cables. In addition, the most electric power systems on the continents are interconnected providing enormous size, while the control is still limited in scope [9].

The end-user segment has also evolved visibly. Indeed, the consumers who were "passive" and did not interact dynamically with the electric energy system are currently in the process of transformation, especially owing to the development of a smart meter and related servers and power generators. For example, they have the ability to manage the load that allows them to participate in resolving some network restrictions, while reducing peak consumption or offering other services required for the system.

In addition, with the development of distributed energy, the end user being a consumer can also become a producer or a source of energy storage. Thus, the consumer becomes "active" or even "overactive" when opportunities arise for control of the load, local energy production or storage, depending on the requirements of the law, market structure or available technologies. In addition, the expected development of hybrid and electric vehicles with their charging characteristics and storage capabilities will contribute to system management complication. These changes inspire engineers and researchers to develop innovative solutions to overcome problems and meet changing needs, minimizing the investments in the system and optimizing the entire energy chain [10].

In the last decade, the dynamic implementation of advanced digital technologies in the industry of the fuel and energy complex takes place, which leads to increasing enterprises efficiency through changes in internal business processes, as well as the modernization of production facilities. Further dynamic development of digital technologies and their practical application in the activities of industry companies will bring about the greater opportunities and economic benefits. As a result, the use of digital technologies in complex solutions will lead to a change in the business environment, as well as to an increase of competition for all industry enterprises [11]. According to the majority of experts' opinions, the scale of this transformation requires a systematic target vision of digitalization at the industry level. In this case, competent government regulation shall be an integral part of digital transformation. The energy industry of the Russian market does not have this experience, however, Skolkovo partners, namely, the French power company EDF, whose leadership indicated the need for a unified communications platform with the participation of companies and the expert community, has formed its integrated position in terms of the challenges of energy industry digitalization several years ago.

The EDF Company that takes the leading position in the European market in terms of its production capacity realizes innovations and modern information and communication technologies as an integral part of its activity, which allow creating smart products that make the consumer life and the environment only better.

In 2015, a unique EDF Pulse platform was created based on the company, this platform combines the innovation and science, thereby providing the initial startups with the opportunity to implement their innovative projects in various areas of life. This initiative met the response of hundreds of working groups involved in the development of innovative products but who had no previous opportunity to implement them [12]. Thus, the EDF gave rise to the development of a certain area of the TPC, namely, the digital power industry that provides for developing the smart products for the consumers life and international companies in conditions of the active digitalization of the most economy sectors.

Based on the above, hereafter I would like to consider the implemented projects of the company, which are based on the digital technology. The presented EDF products are aimed at smarter energy consumption, which underlies the idea of the company's research and production complex to create a new generation of the Smart City.

The personnel of the company research and production center have been developing this concept for more than fifteen years, and during this time they managed to achieve great results. Every year, the EDF Pulse science platform organizes a competition for the best innovative project in one of three categories: "Smart home", "health", "clean energy". The 
"smart home" category takes the leading position, which indicates the concern of project developers about the consumers' health and comfort.

One of the latest developments of the EDF Pulse is the E.quilibre application, which is a kind of on-line service. Access to E.quilibre can be obtained by any customer from their personal account on the official website of the application. The visual interface of the application is quite simple and easy to use, which will not be difficulties for elderly people. This development helps the consumer to monitor the level of energy and gas consumed in real time. In addition, the application allows optimizing energy costs if the consumer uses the smart meter Linky ${ }^{\mathrm{TM}}$ [13].

Linky ${ }^{\mathrm{TM}}$ is an advanced next-generation meter built on the remote control technology for remotely transmitting data over a distribution network. In a period between 2013 and 2015, a trial run of this project was carried out, the it results in creating two hundred and fifty thousand meters of the distribution network using the smart Linky ${ }^{\mathrm{TM}}$ meter [14]. The EDF is planning to install the distribution network of thirtyfive million meters throughout France by 2020 based on the innovative Linky ${ }^{\mathrm{TM}}$ technology.

Efficient operation of distribution networks is ensured by "smart" meters, which provide consumers with quick access to the energy consumption data. In addition, this technology has the function of recognizing a problem that has occurred on the problem line from remote access without requiring a specialist call and spending diagnostics time.

Another development that controls the amount of payments for electric power and allows you to adjust the room air temperature is the Sowee.

The Sowee device is a control panel modification, which is set to control room heating, as well as to control all "smart" devices operation within a radius of one hundred meters, which will provide maximum comfort. This project has been presented on the French market since the end of 2016, and the EDF is planning that every fifth consumer will use the Sowee device in the next ten years [15].

In the further perspective, the EDF research and production center is planning to update this project for consumers who use electric cars and solar panels in everyday life. The advanced Sowee device will be designed for independent control and autonomous monitoring of energy production of all "smart" devices available to the consumer.

With regard to electric cars, dozens of multifunctional mediation and information points (PIMMS) have already been created specifically for consumers who may suddenly encounter the problem of access to the special energy sources [16]. This project was created by the EDF with the support of partners and state services involved in coordinating the activities of social services in various regions of France. Currently, the project has been implemented in the amount of fifty-five centers, which were originally located in the largest cities of France, but now they are actively spreading to rural areas owing to mobile network structures.

\section{DISCUSSION}

For many years, leading experts in the field of information and communication technologies, innovations and IT technologies have been researching creation of the Smart City concept, an integral part of which was the idea of the complete automation of all processes that make consumers life more practical and comfortable [17]. However, relatively recently, the leaders of the global electric power market have thought about the problem regarding the protection of the environment, health and safety of consumers, thus, setting themselves the task of "clean" energy production without damage to the consumers health and the general condition of the ecosystem of our planet [18].

The Russian electric power market does not have the implemented projects of such value as the above experience of the French energy company, the EDF. The current-day realities impose their strict requirements for the energy market, and to take the leading positions, the fuel and energy complex of Russia has to create a fundamentally new and powerful platform, which will be based on a set of measures in key trends mentioned in the Ministry of Energy project "Digital Energy".

- Digital Transformation Coordination System of RF PEC;

- Unified information and communication energy environment;

- The regulatory base of production capacities and the regulatory framework governing the new "digital" structure of energy;

- Training of highly qualified personnel with unique competencies;

- Digitalization of the FEC management and supervisory activities at the state level.

The approach used by the EDF to change internal business processes and bring digital technologies in the energy industry to a new level allowed the company to create a balance, on the one hand, incentives for successful process development of companies and attract investment, and, on the other hand, requirements for ensuring reliability and safety of FEC facilities. In addition, a single look at the priorities of digital transformation at the industry level will create a trusted digital environment based on the general standards. It will join various digital solutions and maximize all the advantages that digitalization brings and accelerate the export of high-tech Russian solutions.

\section{CONCLUSIONS}

The national energy market set the priority for the victory in the global technological race and the formulation of the targeted digitalization trend that will ensure combination of the financial and intellectual potentials. Smart grids, digital substations, renewable energy - all these are being actively implemented in the Russian energy sector.

The digital technologies propose creation and implementation of new methods for communication with consumers. If previously the interaction between the companies and consumers was one-way: consumers learned about goods and services through advertising and the media, 
currently, there is feedback, where customers' opinion plays the more important role than the advertising in the media.

The digital technologies affect all critical elements of the organization as such the possibility of integrated survey concerning the readiness for these transformations. The effective digital transformation of an enterprise requires mastery in two types of leading activities: in developing the innovative ideas and implementing them in all organization business processes [18].

For effective development in conditions of digital transformation in the energy sector, the enterprises need to have a suitable management strategy and a number of competencies. Thanks to the mentioned components, the organization will be able to more flexibly accept the internal and external changes of its business processes and successfully create innovative products and business models.

Thus, the enterprise will retain their organizational ability regardless of the range activity, be able to balance the accumulated and gained experience, creation and modification of new management strategies

The energy industry digitization only gets starting now but there is active work going on implementation of innovative solutions relating to production at enterprises, creation of new specific, unique oversight functions at the state level, transformation of professional education to train future specialists in the field of digital energy.

The key results of implementation of these measures shall be upgrading the efficiency of enterprises activity in the fuel and energy sector of the Russian economy, optimization of the business processes of "smart" gas distribution networks and electric "smart" networks, enhancement of the level of technical condition of production assets of the electric power industry and reliability growth of power supply to consumers.

\section{REFERENCES}

[1] E. S. Balashova, "Estimation of production reserves contributing to creating an effective and efficient production system," Information management systems, vol. 6, 2014, pp. 123-128.

[2] M. Hammer, "Faster, better, cheaper: Nine methods of business process reengineering," Moscow: Alpina Publisher, 2012, p. 356

[3] G. Girsberg, "World networking," Deutschland, 2014, pp. 43-47.

[4] D. Jeston and J. Nelis. "Business process management. A practical guide to the successful implementation of projects," Moscow: Simvol, 2015 , p. 512.

[5] T. N. Yudina and I. M. Tushkanov, "Digital economy through the prism of the philosophy of economy and political economy", Economy Philosophy, vol. 1, 2017.

[6] I. M. Tushkanov and T. N. Yudina, "Acceleration of Digital Economy," System simulation of sociological and economic processes: Proceedings of the 39th International Scientific SchoolSeminar, Saint Petersburg, September 30, October 6, 2016 , edited by Dr. sc. oec V.G. Grebennikova, Dr. sc. oec I.N. Schepina Voronezh: Voronezh State Pedagogical University, 2016.

[7] T. N. Yudina, "Understanding the Digital Economy," Modernity: Economy Algorithms and Practices: collected works, edited by Yu.M. Osipova. Moscow and Tambov: Publishing House TSU named after G.R. Derzhavin, 2016.

[8] V. P. Kupriyanovsky, D. E. Namiot, S. A. Sinyagov, and A. P. Dobrynin, "Works on the digital economy," Modern Information Technologies and IT Education, vol. 12(1), 2016.

[9] V. Yu. Katasonov, "Digital Finance. Crypto currencies and electronic economy. Freedom or concentration camp?", Moscow: Knizhny Mir, 2017
[10] M. A. Sneps-Sneppe and D.E. Namiot, "On Open Source Smart City Platform: How to Get It?", Modern Information Technologies and IT Education, Vol. 12(1), 2016.

[11] A. L. Texler, "Digitalization of energy: from process automation to digital transformation of the industry," Energy Policy, 2018.

[12] Official website of the EDF [Electronic resource], URL: https://www.edf.fr/en/the-edf-group/industrialprovider/renewableenergies (Accessed date: 21.01.2019).

[13] Official website. Atomic energy industry 2.0 - Electricite de France (EDF) [Electronic resource], URL: http://www.atomicenergy.ru/EDF (accessed date: 21.06.2019).

[14] Official website of the EDF representative office in Russia and the CIS countries, Electric power: innovative approach [Electronic resource]. - $\quad$ URL: https://russia.edf.com/ru/metahome/homepageedf-in-russia-ru (accessed date: 21.06.2019).

[15] D. V. Kholkin and I. S. Chausov, "Digital transition in the energy sector of Russia: search of meaning," Energy Policy, vol. 4, 2018, pp $8-17$.

[16] L. V. Massel, "Methods and smart technologies for the scientific justification of strategic decisions on the digital transformation of energy," Energy policy, vol. 4, 2018, pp. 30-41.

[17] F. V. Veselov and V. V. Dorofeev, "Smart energy system of Russia as a new stage in the development of the electric power industry in the digital economy," Energy Policy, vol. 4, 2018, pp. 43-57. 